@CEDA/TU, 2017, US Library of Congress, Catalog Card No.: 79-915209, ISSN: 2091-0339

The Journal of Development and Administrative Studies (JODAS), Vol. 25(1-2), pp.62-75

\title{
Sexual Violence and Consequences of Unintended Pregnancy among the Street Based Sex Workers in Nepal
}

\author{
Rita Karki ${ }^{1}$
}

\begin{abstract}
Unintended pregnancy, concerning particularly in street based female sex workers (SFSWs) who solicit in streets or public places for sex, is closely associated with sexual relation involuntarily and often unwillingly. It seriously challenges in physical, mental, social and economic wellbeing hazardously. The aim of the study is to explore the sexual violence, use of contraception and events and consequences of unintended pregnancy, the study of which is lacking up to the present time in Nepal. A cross-sectional study is conducted using mixed method consisting of questionnaire-based survey with 110 SFSWs along with case studies and observations. Respondents are identified by using snowball sampling technique. The findings are presented descriptively after arranging in different themes. Results show that almost all the SFSWs had experienced sexual violence at least once after involving in sex trade; 74 percent had threatening experience and 87 percent induced abortion among the unintended pregnancy from clients. The results indicate that the forced prostitution and threatening experience to follow clients' interest and unprotected sex are significantly hazardous for SFSW' overall health. High prevalence of sexual violence and unintended pregnancy result in poor health outcomes for SFSWs. Assuring the sexual health and life safety of SFSWs from group sexual violence is another risk area for further exploration.
\end{abstract}

Keywords: sexual violence, unintended pregnancy, clients, forced prostitution, condom, abortion

\section{Introduction}

Sexual violence is a major public health concern with substantial negative impacts on morbidity and mortality, including poor sexual and reproductive health outcomes as well as human rights violation. It takes devastating toll on women's lives, on their families, and on society as a whole (Misganaw \& Worku, 2013 and Argento, Muldoon, Duf, Simo, Deering \& Shnnon, 2014). The pervasive levels of gender based violence among female street-based sex workers leads maternal health to critical condition and it is directly and indirectly related to the effects, like immediate and long-term unwanted pregnancy, abortion, gynecological complications including imposing appreciable socio-economic burden on individuals and society. They are also exposed to risk (Weldegebreal, Melaku, Alemayehu, \& Gebrehiwot, 2015) of depression, chronic pain and post traumatic stress disorder who have experienced a shocking, scary, or dangerious event and may feel stressed or frightened even when they are not in danger (Argento, et al., 2014; Jares, Chang, Choi, Zheng, He, \& Huang, 2015; NIMH, 2013 and Yazdkhasti, Pourreza, Pirak, \& Abdi, 2015).

\footnotetext{
${ }^{1}$ Lecturer, Department of Population Studies, Ratna Rajya Laxmi Campus, Trubhuvan University, Kathmandu Corresponding mail: karkirita2010@gmail.com
} 
Female sex workers with a history of psycho-social distress were less likely to require clients to use condoms, and engaged in more risky sex practices overall. Among FSWs who do not wish to become pregnant, unintended pregnancy may be understood as an occupational health risk of sex work. Low use of contraception and inadequate access leads to a high burden of unintended pregnancy and poor reproductive health outcomes, including risk of maternal morbidity and mortality (Jares, Chang, Choi, Zheng, He, \& Huang, 2015; CHANGE, 2016 \&Schwartz, et al., 2015). In Kunming, China, about half of the respondents reported one or more lifetime abortions where inconsistent condom use, frequent alcohol use and longer-term cohabitation were associated with prior abortion. (Zhang, Kennedy, Temmerman, Li, Zhang, \& Luchters, 2014).

In Canada over the past two decades, urban centers have experienced epidemics of violence against street based female sex workers. The findings document concluded that they victimized from extremely high prevalence of both sexual and physical violence against female sex workers that persist because of large scale structural inequities which includes the factors, like homelessness, inability to access drug treatment, servicing clients in cars or public spaces, and enforcement based policing strategies were independently associated with gender based violence in Vancouver, Canada (Shannon, Kerr, Strathdee, Shoveller, Montaner, \& Tyndall, 2009). The women who work as prostitutes are in hock and in trouble. Prostitution is rarely, if ever, a choice (Bindel, 2017) but sex workers have diffcult situation to escape from sex trade after they involved once in this profession because of economic constraints as well as networking of pimps and clients (Waltman, 2011).To maintain their daily life and their children's economic problem appears as the real problem more than she is (Dworkin, 1993).The sexual violence is severely reoccurring in this profession in the absence of clear legal system in Nepal and SFSWs are being victimized from not only the safe sex life, but also are exposed to the risk of unintended pregnancy and their critical painful consequences experienced from different perpetrators.Sexual violence and consequences of unintended pregnancy among the street based sex workers who solicit as streets or public places (MoHP, 2010) have not been widely studied in Nepal. The aim of this study is, therefore, to explore the situation of sexual violence and consequences, use of family planning to prevent unwanted pregnancy and event and consequences of unwanted pregnancy from clients.

\section{Literature Review}

Generally, commercial sex is related in dealing with sexual service and money. The kind and structure of sex work differ considerably around the globe. Those who sell sex might work with or without a facilitator or controller through establishments, such as bars, brothels, or in more public spaces, such as parks and streets (Kakchapati, Singh, Rawal, \& Lim, 2016). Normally, they have occupied an anomalous and marginal position in societies. Hughes, (2000) argued that sex trade is not the world's oldest profession, as is commonly said, although it is probably one of the world's oldest forms of men's violence against women and girls. So the designation of sex work is also a special human right issue. Violence against FSWs is pervasive in both developed countries and lower-to-middle-income countries. Globally, client-perpetrated violence against FSWs has been associated with multiple healthrelated harms, including high-risk sexual behavior and increased exposure to HIV/STIs. They are often exposed to work-related traumas in the form of sexual, physical, and economic violence perpetrated by clients (Semple, et al., 2015). These women, who engage in the provision of sexual services for commercial consideration, put themselves at special risk of health problems for a variety of reasons. They are subject to considerable risks of physical abuse, including beatings and rape. Frequent sexual contact with a variety of partners makes these women especially vulnerable to STI, HIV/AIDS (CREHPA, 2001). 
Violence has long been assumed to be an intrinsic trait of female prostitution (Ribeiro \& Sacramento, 2005). Commercial sex is compulsion for sex workers due to economic needs and they have high prevalence of violence. They encounter different socio-economic and health problems, including STIs/HIV, unintended pregnancy and complications from unsafe abortion, stigma, violence, and drug addiction (Gupta, Dandona, Alary, \& Dandona, 2014 and Phrasisombath, Faxelid, Sychareun, \& Thomsen, 2012).Client turnover plays a role; the more clients a sex worker serves, the more likely she is to encounter one who is infected, and thus to become infected herself. On the streets, seven in ten younger female sex workers said they had been raped or beaten in the past year, twice the rate of violence reported by older female sex workers in Bangladesh (UNAIDS, 2004).

Violence against women is an important risk factor for unintended pregnancy (Gomez, 2011). In a study of 294 female street-based prostitutes in Miami, Florida, 76\% reported experiencing violence in the last 90 days just before the survey was conducted.(Kurtz, Surratt, Inciardi, \& $\mathrm{Ki}, 2004)$. They have high rates of unintended pregnancy. Modern contraceptive uptake is surprisingly low, which in turn has a high rate of unintended pregnancy. The study conducted in Kenya, Luchters, et al., (2016) showed that there is low use of modern contraceptive methods among female sex workers has a high rate of unintended pregnancy which results in financial hardship, social stigma, risk of abandonment, or dangerous abortion practices. Among the 400 FSWs, in Mombasa, Kenya,57 percent reported using a modern contraceptive method. Over one-third (36\%) of women were using condoms inconsistently without another method. In their study, they found 24 percent had an unintended pregnancy during the study. Similarly, a study showed that the magnitude of unintended pregnancy among female sex workers in the past two years was $28.6 \%$ among the 346 FSWs in Mekelle city, northern Ethiopia where failure to use condom with steady partner was the major reason for almost two third (61.6\%), of the respondents to have unintended pregnancy (Weldegebreal, et al., 2015).The result reveals that the unintendend pregnancy cases occurred whilenot using condom regularly and proporly with clients. The consequences of unwanted pregnancy might be very painful in their life because they are vulnerable for not only STIs and HIV/AIDS, but also abortion cases and birth and raring and caring of children which make them difficult in their life.

Generally, poverty and unemployment in rural areas force individuals or families to migrate to the urban areas. A study showed that most of the street based female sex workers $(89.1 \%)$ were migrated from different parts of the country in Kathmandu city. (Karki, 2015).Most of these females involve in sex trade because of unemployment, limited work opportunities, and poor salaries in other jobs (Yadav, 2008).Sex work reflects as occupational hazards and FSWs are more vulnerable due to multiple factors: large numbers of sex partners, unsafe working conditions, barriers to negotiating condom use, social stigma \& marginalization, criminalized work environments (WHO, 2012). Thus, unsafe sex practices between FSWs and their clients are not uncommon. The most recent Integrated Biological and Behavioral Surveillance (IBBS) surveys among FSWs in Kathmandu, Pokhara, and Terai highway districts revealed that consistent condom use with clients over past 12 months was not satisfactory and the consistent condom use with nonpaying partners in Kathmandu and Pokhara was even lower (Kakchapati, et al., 2016).The nature of sex work is itself in high risk due to multi partner sex and reoccurring the sexual violence against female sex workers in this profession. Different literatures clearly indicate that the street based female sex workers are more vulnerable than others (i.e. establishment based). They are in high risk of unintended pregnancy including STIs and HIV/AIDS. Some research studies focus the prevalence of SITs and HIV/AIDS among the sex workers in Nepal. Therefore, it is needed to explore the hidden facts with 
insiders' views related to the situation of sexual violence and its different consequences. This study presents the issues particularly events of sexual violence and perpetrators and its consequences, currently using condition of contraception, events of unintended pregnancy and its consequences of street based female sex workers.

\section{Methodology}

This study employed a mixed method approach which included a survey in Kathmandu valley taking 110 SFSWs, 21 case studies with voice recording and non participant observation based on cross sectional design. The qualitative data were transcribed, translated and analyzed in different themes triangulating with the quantitative data which were analyzed statistically. Snowball sampling technique was used to find the eligible respondents in the target research area which was purposively selected in 2013. To find out the initial eligible respondents, I did contact with the same respondents who were used in my Master's degree research some years ago, related in the same field, a large number of SFSWs were in contact with me. Among them some (who were continuing the same profession in the same location) were regular get in touch with me and I found them in the beginning and started collecting the information for this study. Information was performed to describe the sexual violence and their perpetrators, consequences of sexual violence by selected socio-demographic characteristics and assessed the use of family planning methods to prevent clients' pregnancy and consequences of unintended pregnancy relating them in different themes. Verbal informant consent was taken before starting the interview and voluntary participation and confidentiality was maintained by hiding their real identities during the research time.

\section{Results}

\subsection{Experience of Sexual Violence}

All the respondents reported that they ever experienced serious types of sexual abuse as defined by UNICEF (2001) and UNFPA AFPPD, Government of Japan (2003) while they are in this profession. Although different perpetuators involved in sexual violence against sex workers, they were mainly suffered from clients $(90 \%)$, husband $(62 \%)$, police $(44 \%)$, and relatives $(29 \%)$. One third respondents were victimized from forced prostitution; about three in four suffered from sexual relation with threatening, one fourth SFSWs were victimized from rape and 27 percent were compelled to accept forced pregnancy.

Generally, the silent legal system, i.e. no clear legal provision about their profession and male dominated sexual behavior adversely affect in SFSWs' overall health which is also public health concern because of multi partner sex. Unsafe sexual practices, i.e. not using condom properly and regularly is not only the critical situation of SFSWs to obtain the reproductive health and reproductive right, cruel inhuman practices from different perpetrators are highly punishable issue to address the social justice and acceptable human life.

The forced prostitution is taken as serious type of sexual violence. Though there are different perpetrators involving in this type of violence, involving as a force from their own husbands seems to be more serious event. Some of the experiences of some SFSWs shared how their husbands directly or indirectly forced them to involve in the sex work.

...He (ex-husband) was drunkard. He sold all my ornaments for drinking. He used FSWs before I had entered in the sex trade and he knew that the earning was good in the sex trade and he made me trap to involve in this profession (Literate, 33 yrs). 
She shared her experiences before she was separated with her husband who forced her to enter to the sex work. After that she was gradually compelled to accept the profession so that she could maintain their daily life.

...my husband was sitting outside a hotel's room. But he (husband's friend) closed the hotel's room and raped me. I became faint. He poured a bottle of water over my body and made me conscious. My neck and some parts of body had scars. I was so hunger at that time. I could not escape from there. He gave me 1000 Rs. But husband took the money immediately which I got when I came out from the room. (Illiterate, 34 yrs).

Table 1: Experiences of Sexual Violence of Sex Workers by Different Perpetrators (in percentage)

\begin{tabular}{|c|c|c|c|c|c|c|c|c|}
\hline \multirow[b]{2}{*}{$\begin{array}{l}\text { Types of Sexual } \\
\text { Violence }\end{array}$} & \multicolumn{7}{|c|}{ Perpetrators } & \multirow[b]{2}{*}{$\begin{array}{l}\text { Total } \\
\text { N) }\end{array}$} \\
\hline & Husbands & Clients & Police & Relatives & SFSWs & Employers & $\begin{array}{l}\text { Street } \\
\text { Boys }\end{array}$ & \\
\hline $\begin{array}{l}\text { Sexual relation with } \\
\text { threatening }\end{array}$ & 29.4 & 73.7 & 37.5 & 9.4 & - & 14.3 & 61.5 & 84 \\
\hline $\begin{array}{l}\text { Sexual harassment } \\
\text { at work place }\end{array}$ & 2.9 & 59.6 & 72.9 & 6.3 & 66.7 & 42.9 & 61.5 & 79 \\
\hline Marital rape & 80.9 & - & - & - & - & - & - & 47 \\
\hline Forced prostitution & 32.4 & - & - & 21.9 & 41.7 & 42.9 & - & 36 \\
\hline Forced pregnancy & 17.6 & 27.3 & - & - & - & - & 7.7 & 30 \\
\hline $\begin{array}{l}\text { Sexual harassment } \\
\text { at home }\end{array}$ & 17.6 & 1.0 & - & 50 & - & - & - & 28 \\
\hline Rape & 2.9 & 19.2 & 6.3 & 21.9 & & - & 61.5 & 27 \\
\hline Forced marriage & 1.5 & - & - & 21.9 & - & - & - & 7 \\
\hline Total (N) & 61.8 & 90.0 & 43.6 & 29.1 & 10.9 & 6.4 & 11.8 & 110 \\
\hline
\end{tabular}

Percentage total may exceed 100 due to multiple responses

It reveals that the husband set the background to involve her in the sex work. In an informal talking, she shared to me that her husband was a regular drunkard and he needed to more money for drinking. Later she knew that her husband's friend who raped her was client. These types of activities which her husband forced her to do time and again and slowly it became her profession. Another SFSW shared a similar experience in which her husband intentionally made her compelled to start and continue the profession as:

.... One day, my husband and I went to visit the busy town of Kathmandu. Suddenly, I didn't see him. I hurried up. At that time, some females were watching and requesting me as being sex workers. I wept more. I tried to deny strongly.... But they motivated me as more money could easily be earned from this profession. At that time I couldn't escape from there. After some days my husband came to take me. Later I knew that my husband was client of those sex workers and he left me among those groups of sex workers to earn money (Illiterate, 45 yrs).

Many women reported that they had experienced critical condition of sexual violence. Forced pregnancy and rape cases were reoccurring among the SFSWs by different perpetrators like clients, police, husband, street boys and relatives. Some SFSWs shared their experienced as:

At the time of searching clients, a boy appeared and proposed me to visit a temple. We were walking on the way beside the jungle of the temple. He forced me to go into bush from near the way. There were other two boys hiding behind the bush. I hurried up. Anyway I requested them to use condom which I had. But they rejected my words. I had also threatened them to 
bite...if they did not use condom. After then they used condom and raped me turn by turn and they escaped from there without giving me the money which I requested. (Literate, 52 yrs,)

...The breakdown of our relation (husband and wife) took about 3 years. He knew well about my profession because he was also one of the clients. One day I was busy in kitchen at my room. Suddenly he came in my room. He tried to convince me for reunion but I did not want to stay with him. He started to touch me unnecessarily and he raped me. His strong hand used to close my mouth. I could not fight against rape... (Illiterate, 37 yrs).

... There was a doctor who involved in treating us STIs and HIVIAIDS. Sometimes he teased me without any reasons. He started to touch my sensitive organs unnecessarily. One day he called me for a work, but he caught arm strongly and pushed me into toilet. Then he forced me to have sex without condom. The corner of hospital was sometimes also used for sex with standing position without condom. He put 200 Rupees in my hand. (Literate, 52 yrs).

Some time, police are also involving in violence against SFSWs instead of preventing it. SFSWs frequently stated that they compelled to provide free sex in order to protect her from potential sexual abuse. Some of them mentioned as:

..I opposed to participate in sex without condom but he loudly threatened me to be naked for sex. I was trying to cry but, he strongly closed my mouth by using his hand and raped me. He was a police, because I saw him many times in police uniform in Hunumandhoka, a police office (Illiterate, 36 yrs).

I am free from police arresting when I started to provide free sex for him at the time as his interest (Illiterate, 28 yrs).

...I visited a client and provided sexual service as his interest but he denied to give money and threatened me that "I will arrest you if you talk about money". Some of my friends became arrested when they opposed these kinds of clients. (Illiterate, 31 yrs).

When police arrested us and we were into a van but police abused us saying with very dirty words. It was very difficult to hear. In addition, they used their boots and sticks to push our sensitive part and organ of the body. Police never can be a human being and they never show humanity (Illiterate, 34 yrs).

\subsection{Consequences of Sexual Violence}

Most of the SFSWs (106 out of 110) reported that they had experienced fear after they were coerced into different types of sexual violence. Most of the SFSWs appeared in the condition of drinking alcohol and smoking at the time of interviews (from observation). They mentioned that they needed alcohol and smoking to be friendly mainly with clients and it makes easy to give clients' satisfaction and also helps to avoid sexual pain. One respondent explained:

... Alcohol and smoking is the best friend in my life. It makes me tension free and pain free. Clients are satisfied if I use more alcohol and smoking (literate, 36 yrs)

Similarly, 71 percent of SFSWs were victims from depression (feeling not happy, frequently weeping, not concentrated in work, feeling not sleepy, irritation, etc.). In the same way, the other serious consequences appeared in sexual violence victims, such as suicide practice (23\%), 10 percent of them suffered from painful and hazardous consequences like mental disorder, illness, faints, aggressiveness and unwanted pregnancy. 
Table 2: Different Consequences of Sexual Violence among Sex Workers

\begin{tabular}{|c|c|c|}
\hline Different Consequences of Sexual Violence & $\mathbf{N}$ & $\%$ \\
\hline Fear & 106 & 96.4 \\
\hline Depression & 78 & 70.9 \\
\hline Humiliation & 54 & 49.1 \\
\hline Loneliness & 49 & 44.5 \\
\hline Alcohol and Drug abuse & 39 & 35.5 \\
\hline Smoking & 36 & 32.7 \\
\hline Laziness & 28 & 25.5 \\
\hline Suicide practice & 25 & 22.7 \\
\hline Others * & 11 & 10.0 \\
\hline Total & 110 & 100.0 \\
\hline
\end{tabular}

Percentage total may exceed 100 due to multiple responses

*Mental disorder, illness, faints, aggressiveness, unwanted pregnancy

But respondents could not defend against the sexual violence effectively because there was no option to complain in appropriate practical legal agency to fight against it. Some respondents described their experiences as such:

Sometimes, I spent the whole night with him (a regular client). He is about 60 years old. He gives me desirable money but he gives me so trouble in sexual intercourse. One day I saw that he used a medicine in front of me and after some time he was changed and became active for sex. I took that medicine cover secretly and took inquiry in a medical person about that medicine and I knew that he used a medicine (Viagra) to be active in sexual intercourse. He did not want to use condom. I became pregnant 3 times, I compelled to spend more money to avoid his pregnancy than what I earned money from this profession (Illiterate, 44 yrs).

...I drink alcohol more to avoid pain at the time of hanging (activity for suiciding) but I was unable to hang properly because of dizzying problem (Illiterate, 4lyrs).

...I wanted to die myself. One day I used poison, which is used to kill the mice, but some of my SFSW friends saved my life. 'I should have never got daughter's life'. (Literate, 37 yrs).

\subsection{Consequences of Sexual Violence According to Some Selected Socio-demographic Characteristics}

The study shows that one fifth of them were literate from informal education and remaining (18.2\%) got primary education. Only 4.5 percent SFSWs had some secondary and above and nearly 2 percent had $10+2$ level education (not shown in table). It reveals that the level of education was poor among the literate SFSWs. Illiterate SFSWs were suffered more from different serious consequences of sexual violence like humiliation, loneliness, using alcohol including drug and smoking, laziness and others (mental disorder, illness, faints, aggressiveness, unwanted pregnancy) comparing with the literate ones. However, more literate SFSWs were victim from fear, suicide practice and depression than the illiterates. Similarly, fear, suicide practice, depression, and other consequences seemed to be more in the 25-34 age group population. The Study found that the youth population (15-24) was affected more from humiliation, laziness and compulsion to use of alcohol and smoking. 
Table 3: Consequences of Sexual Violence of Sex Workers by Some Socio-demographic Characteristics(in percentage)

\begin{tabular}{|c|c|c|c|c|c|c|c|c|c|c|}
\hline $\begin{array}{l}\text { Socio-demographic } \\
\text { Characteristics }\end{array}$ & Fear & $\begin{array}{l}\text { Humilia } \\
\text { tion }\end{array}$ & $\begin{array}{l}\text { Suicide } \\
\text { practice }\end{array}$ & $\begin{array}{l}\text { Lonelin } \\
\text { ess }\end{array}$ & $\begin{array}{l}\text { Depressio } \\
\text { n }\end{array}$ & $\begin{array}{l}\text { Alcohol } \\
\text { Use }\end{array}$ & Smoking & $\begin{array}{l}\text { Lazine } \\
\text { ss }\end{array}$ & Others & $\begin{array}{l}\text { Total } \\
\text { (N) }\end{array}$ \\
\hline \multicolumn{11}{|l|}{ Literacy Status } \\
\hline Literate & 98.2 & 42.1 & 28.1 & 43.9 & 75.4 & 24.6 & 26.3 & 24.6 & 8.8 & 57 \\
\hline Illiterate & 94.3 & 56.6 & 17.0 & 45.3 & 66.0 & 47.2 & 39.6 & 26.4 & 11.3 & 53 \\
\hline \multicolumn{11}{|l|}{ Age Group } \\
\hline $15-24$ & 92.9 & 57.1 & 14.3 & 42.9 & 42.9 & 50.0 & 42.9 & 35.7 & 0.0 & 14 \\
\hline $25-34$ & 100.0 & 41.2 & 29.4 & 50.0 & 76.5 & 26.5 & 29.4 & 20.6 & 11.8 & 34 \\
\hline $35-44$ & 91.2 & 50.0 & 23.5 & 35.3 & 67.6 & 44.1 & 32.4 & 17.6 & 11.8 & 34 \\
\hline $45+$ & 100.0 & 53.6 & 17.9 & 50.0 & 82.1 & 28.6 & 32.1 & 35.7 & 10.7 & 28 \\
\hline \multicolumn{11}{|l|}{ Caste/Ethnicity } \\
\hline Brahmin/Chhetri & 100.0 & 40.6 & 28.1 & 43.8 & 71.9 & 21.9 & 25.0 & 25.0 & 9.4 & 32 \\
\hline Janajaties & 97.9 & 57.4 & 19.1 & 46.8 & 63.8 & 40.4 & 38.3 & 27.7 & 10.6 & 47 \\
\hline Madheshi/Muslim & 88.0 & 48.0 & 20.0 & 44.0 & 88.0 & 48.0 & 36.0 & 28.0 & 12.0 & 25 \\
\hline Dalit & 100.0 & 33.3 & 33.3 & 33.3 & 50.0 & 16.7 & 16.7 & 0.0 & 0.0 & 6 \\
\hline \multicolumn{11}{|l|}{ Marital Status } \\
\hline Never married & 90.9 & 36.4 & 9.1 & 27.3 & 54.5 & 27.3 & 27.3 & 18.2 & 0.0 & 11 \\
\hline $\begin{array}{l}\text { Currently married \& } \\
\text { cohabiting/ living } \\
\text { together }\end{array}$ & 92.6 & 53.7 & 20.4 & 53.7 & 68.5 & 38.9 & 33.3 & 27.8 & 14.8 & 54 \\
\hline Widow & 93.8 & 31.2 & 12.5 & 37.5 & 68.8 & 12.5 & 6.2 & 18.8 & 0.0 & 16 \\
\hline $\begin{array}{l}\text { Separated/ } \\
\text { Divorced }\end{array}$ & 100.0 & 55.2 & 37.9 & 37.9 & 82.8 & 44.8 & 48.3 & 27.6 & 10.3 & 29 \\
\hline \multicolumn{11}{|l|}{ Ecological Zone } \\
\hline Mountain & 94.7 & 57.9 & 26.3 & 52.6 & 68.4 & 31.6 & 36.8 & 21.1 & 5.3 & 19 \\
\hline Hill & 36.4 & 61.8 & 34.5 & 34.5 & 21.8 & 9.1 & 36.4 & 61.8 & 34.5 & 55 \\
\hline Terai & 48.4 & 83.9 & 45.2 & 25.8 & 25.8 & 12.9 & 48.4 & 83.9 & 45.2 & 31 \\
\hline India & 80.0 & 100.0 & 0.0 & 40.0 & 80.0 & 20.0 & 80.0 & 100.0 & 0.0 & 5 \\
\hline \multicolumn{11}{|c|}{ Events of pregnant from clients } \\
\hline Yes & 48.7 & 30.8 & 41.0 & 79.5 & 48.7 & 35.9 & 25.6 & 15.4 & 48.7 & 39 \\
\hline No & 46.5 & 66.2 & 28.2 & 31.0 & 25.4 & 7.0 & 46.5 & 66.2 & 28.2 & 71 \\
\hline \multicolumn{11}{|c|}{ Types of treatment get from society } \\
\hline Hated & 100.8 & 52.7 & 25.5 & 45.5 & 70.9 & 40.0 & 38.2 & 27.3 & 16.4 & 55 \\
\hline Affection & 100.0 & 100.0 & 0.0 & 100.0 & 100.0 & 0.0 & 0.0 & 100.0 & 0.0 & 1 \\
\hline No care & 96.4 & 35.7 & 25.0 & 46.4 & 64.3 & 42.9 & 35.7 & 25.0 & 3.6 & 28 \\
\hline Don't know & 15.4 & 38.5 & 76.9 & 19.2 & 19.2 & 19.2 & 3.8 & 15.4 & 38.5 & 26 \\
\hline Total & 96.4 & 49.1 & 22.7 & 44.5 & 70.9 & 35.5 & 32.7 & 25.5 & 10.0 & 110 \\
\hline
\end{tabular}

Percentage total may exceed 100 due to multiple responses

Among the different caste and ethnicity, more Madheshi/Muslim were suffered from depression, laziness and others and they used more alcohol as well as smoking. Mainly widow and separated/divorced Indian (the place of origin) respondents who experienced the events of pregnancy from clients and the respondents who got bad treatment from society were experienced more serious consequences of sexual violence than others.

\subsection{Use of Contraception for the Prevention of Pregnancy of Clients}

Means of contraception plays vital role to prevent unwanted pregnancy. Table 4 shows that more than one fifth of respondents adopted permanent method and about 12 percent were using injection. Pills, Coper T, Femidom, and Norplant were also used to control the pregnancy from clients. There were some $(11.8 \%)$ respondents who did not use any means of contraception because they had infertility problem which is serious concern of reproductive health condition. 
Table 4: Use of Contraption for the Prevention of Pregnancy of Clients

\begin{tabular}{|c|c|c|}
\hline Use of contraption & $\mathbf{N}$ & $\%$ \\
\hline Condom & 42 & 38.2 \\
\hline Minilap/Permanent & 29 & 26.4 \\
\hline Injecting & 13 & 11.8 \\
\hline Not use any method & 13 & 11.8 \\
\hline Pills & 8 & 7.3 \\
\hline Coper T & 3 & 2.7 \\
\hline Femidom & 1 & 0.9 \\
\hline Norplant & 1 & 0.9 \\
\hline Total & 110 & 100.0 \\
\hline
\end{tabular}

The dual role of condom is important in this profession for controlling both unwanted pregnancy and sexually transmitted infections. Study found that SFSWs were using different types of means of contraception. Basically, 38.2 percent respondents used condom to prevent pregnancy from clients (Table 4). It would be good result if it is used in correct way. But the inconsistent or denial use of condom and offering extra money for sex without condom were common. Rape cases, sexual relation with threatening, frequent use of alcohol, etc. lead them to risk of unintended pregnancy, abortion and their consequences. Induced abortion was common among the pregnant SFSWs.

\subsection{Consequences of Unintended Pregnancy Events from Clients}

Study found that more than one third $(35.5 \%)$ respondents experienced unwanted pregnancy form clients during the sex trade. It was the result of lack of knowledge and practice of use of contraception properly. The huge magnitude of induced abortion (87.2\%) was prevailing among the SFSWs in comparing to birth (25.6\%) and miscarries (20.5\%) among the pregnancy cases. These cases were repeated till sixth times. It is a kind of serious concern in reproductive health and right. It creates the different pregnancy complications and difficulties in their life.

Table 5: Consequences of Unintended Pregnancy Events from Clients

\begin{tabular}{|c|c|c|c|c|c|c|c|}
\hline \multirow[t]{3}{*}{ Consequences } & \multicolumn{6}{|c|}{ Frequencies } & \multirow{3}{*}{$\begin{array}{l}\text { Total } \\
\text { (N) }\end{array}$} \\
\hline & 1 & 2 & 3 & 4 & 5 & 6 & \\
\hline & $\%$ & $\%$ & $\%$ & $\%$ & $\%$ & $\%$ & \\
\hline Abortion & 23.5 & 44.1 & 8.8 & 17.6 & 2.9 & 2.9 & 34 \\
\hline Birth & 60.0 & 30.0 & - & 10.0 & - & - & 10 \\
\hline Miscarries & 25.0 & 50.0 & 12.5 & - & 12.5 & - & 8 \\
\hline Total & 41.0 & 56.4 & 10.3 & 17.9 & 5.1 & 2.5 & 39 \\
\hline
\end{tabular}

Percentage total may exceed 100 due to multiple responses

All the consequences of unwanted pregnancies, abortion, birth, or miscarriage cases made their health condition critical which is the great public health concern. Some respondents shared as following:

"...I thought it is better to abort than to give birth to a baby and care him/her because I did not get afraid of my own death. I visited a medical clinic with the help of one of my clients. I knew that I had eight months baby in my womb. I had shared it with my SFSW friends and they suggested me that the charge should be collected from different clients with saying to them that it is needed for abortion of your baby and so I did. I got succussful abortion to my pregnancy but I have never been healthy after that case..." (Literate, 36 yrs) 
...I had used condom to prevent my unwanted pregnancy. But time and again I was pregnant 12 times. Four babies died after live birth, two babies are living together and remaining six were aborted from three to six months. Because of the more frequent abortion, it is more difficult to be active as I was before and I felt very weak myself. Now it's my compulsion to be tolerant as I am suffering from regular paining to my lower part of stomach." (Iilliterate, 34 yrs)

"...I became so worried and hurried to avoid my unwanted pregnancy. I traditionally heard eating a vegetable 'ashgaurd (Kubindo)' would help me to miscarriage, I did it but it did not help me. According to my SFSW friends I ate some pieces of glass with mixing to Abir (a red dust with chemical used for worshipping god) but it made me serious in health problems and I consulted to doctor for treatment. At that time I did not have any hope to be alive. Luckily my life was saved, I wanted to have baby but I could never be mother." (Literate, 29 yrs)

It is not necessary to use of condom because I used permanent method 'Minilap'. (Illiterate, 45 yrs).

No need to use any type of contraption methods because I never become pregnant (infertility problem) (Illiterate, 35 yrs).

...Among the five babies of clients, two babies immediately died after live birth in the street, one five years baby died in an accident in the road, other one died from diarrhea and rest one died in Mahankal Temple at the time when I left him with a beggar SFSW.... Many people requested me to give my baby to them but I was unable to give them easily. I wanted to be a mother but I am "unlucky mother" (Literate, 36 yrs).

I am suffering from the problems of miscarriage, it is reoccurring within one to four months. Miscarriage is better than giving birth a child because I have no time and money for rearing and caring of children. But, I will probably die because of miscarriage. I admitted frequently in the hospital to control the over bleeding at the time of miscarriage. (Illiterate, 33 yrs).

\section{Discussion}

This study found that all the SFSWs experienced serious types of sexual violence from seven different types of perpetrators after entering in the sex trade although mainly suffered from clients. Most of the respondents were victimized from sexual relation with threatening and sexual harassment at work place and it indicates that they are victimized from rape and compelled to accept forced pregnancies cases which are of major public health concern with substantial negative impacts on morbidity and mortality, including poor sexual and reproductive health outcomes as well as human rights violation (Misganaw \& Worku, 2013 and Argento, et al., 2014). This study shows that some husbands force their wives to involve into sex work which is a kind of cruel inhuman practices. They try to make their wife as a material to earn money especially for their drinking purpose. It shows male supremacy to victimize female. It can be the result of structural gender inequality and subordinate status of female. It is the unique finding of this study. The case histories preveal that experience of different sexual violences and its consequences seriously harm to their life.

The finding of this study supports the previous studies of Argento, et al., (2014) who highlight important factors that high prevalence of recent intimate partner violence among street which is a critical and neglected human rights. They also demonstrate that experiences of intimate partner violence are often an extension of unequal gender roles and power imbalances in relationships; higher gender inequity has been found to be independently associated with increased male-controlled sexual decision making power, perpetration of rape, unprotected sex. 
Particularly, female sex workers are exposed to the risk of unintended pregnancy, abortion and their consequences. Unintended pregnancy is a significant public health concern in the world due to its negative association with social and health effects for both women and their families in particular and to health sector's resources and the public at large (Weldegebreal, et al., 2015; Jares, et al., 2015; CHANGE, 2016 \&Schwartz, et al., 2015). Similar to these explanations, this study found out that the unsafe practices of abortion and their consequences have automatically negative impact in their entire life which is a significant public health concern. About 90 percent SFWs used any modern family planning methods but more than one tenth did not use any such methods. They were easily taken not to use any method because of the problems of infertility and miscarriage. Only 38 percent SFSWs used condom to prevent the pregnancy but it depends on client's interest and proper use of condom. About one third respondents used condom regularly and/but (im)properly. The events of pregnancy $(35.5 \%)$ and the percent of regular and proper use of condom clearly showed the serious consequences of pregnancy and its complication including STIs. They are victimized from serious gynecological health problem including different demographic, social and economic problems. These findings are consistent with the statement given by Eileen, et al., (2013) that modern contraceptives are highly effective at preventing pregnancy, but offer no HIV protection. The cases of unintended pregnancies are automatically linked with sexual violence and unprotected sexual practices. The findings suggest that protective alternative methods for female should be developed to prevent from unsafe sex. Furthermore, they should not depend on only in the condom used by male to be prevented from unprotected sex.

\section{Conclusion}

Poor socio-economic status, ignorance and insufficient knowledge about profession are the root factors to involve in this profession. Different severe type of sexual violences against sex workers which lead them serious types of consequences of physical and mental health problems. It would be compulsion to use of condom properly during the sex with clients for the prevention of unintended pregnancy and STI, HIV/AIDS but denial use of condom from clients, lack of knowledge to use correctly, and offering extra money for sex without condom etc. factors are threatening their health. So the existing reality of relentless type of sexual violence and their consequences among SFSWs are some of the serious challenges to their life which is also significant in public health concern. It needs to medical care for them for both short and long term. It is very difficult to raise the voice against violence of sex workers because it is recognized as socially stigmatized profession and they are unable to deserve the labor rights. The practices of force getting them into sex trade, multi partner unsafe sex and difficult condition to escape from their profession, compulsion to bear the consequences of unintended pregnancy from mother side may be the serious gender issues in this area and the problems need to be addressed from gender lens.

Acknowledgements: This article is based on my research work carried out to fulfill M. Phil. Degree in Population Studies. Author would like to acknowledge Prof. Dr. Ram Sharan Pathak, Head and Prof. Dr. Govind Subedi and research committee of CDPS for providing valuable suggestions for this research paper. Finally, she wishes to show her gratitude to anonymous reviewers for their productive feedback on the draft paper.

\section{References}

Argento, E., Muldoon, K. A., Duf, P., Simo, A., Deering, K. N., \& Shannon, K. (2014). High prevalence and partner correlates of physical and sexual violence by intimate partners among street and off-street sex workers. PLoS ONE, 9 (7), 102-129. 
Bindel, J. (2017, August 19). Most 'sex workers' are modern-day slaves. Retrieved from https://www.spectator.co.uk/2017/08/most-sex-workers-are-modern-day-slaves/

Center for Health and Gender Equality (CHANGE). (2016). All women, all rights: Sex workers included U.S.foreign assistance and the sexual and reprouctive health and rights of female sex workers. New York Washington, DC. Retrieved from http://www.genderhealth.org/files/uploads/All_Women_Alll_Rights_Sex_Workers_In cluded_Report.pdf

CREHPA. (2001). A situation assesment of sex workers. Kathmandu: CREHPA.

Dworkin, A. (1993). Prostitution and male supremacy. Michigan Journal of Gender and Law, 1 (1), 1-12. Retrieved from https://repository.law.umich.edu/cgi/viewcontent.cgi?referer $=\&$ httpsredir $=1 \&$ article $=1$ $191 \&$ context $=$ mjgl

Eileen, Y. A., Mnisi, Z., Mnisi, Z., Mabuza, X., Kennedy, C., Kerrigan, D., et al. (2013). Use of dual protection among female sex workers in Swaziland. PubMed, 29 (2), 69-78. doi: $10.1363 / 3906913$

Gomez, A. M. (2011). Sexual violence as a predictor of unintended pregnancy, contraceptive use and unmet need among female youth in Colombia. Journal of Women's Health, 20 (9), 1349-56. Retrieved from

http://socialwelfare.berkeley.edu/sites/default/files/docs/gomez_sexual_violence_2011 .pdf

Gupta, A. K., Dandona, R., Alary, M., \& Dandona, L. (2014). Predictors of HIV prevalence among street-based female sex workers in Andhra Pradesh state of India: A districtlevel analysis. BMC Women's Health. doi:org/10.1186/1472-6874-14-65 , 2-8

Hughes, D. (2000). Men create the demand; women are the supply. University of Rhode Island. Retrieved from http://www.uri.edu/artsci/wms/hughes/demand.htm

Jares, K. H., Chang, R. C., Choi, S., Zheng, H., He, N., \& Huang, Z. J. (2015). Intimatepartner and client-initiated violence among female street-based sex workers in China: Does a support network help? PLoS ONE, 10 (9).

Kakchapati, S., Singh, D. R., Rawal, B. B., \& Lim, A. (2016). Sexual risk behaviors, HIV, and syphilis among female sex workers in Nepal. HIV/AIDS - Research and Palliative Care, 9, 9-18. doi.org/10.2147/HIV.S123928

Karki, R. D. (2015). Situation analysis of street based female sex workers: Violence experiences of women in Nepal. (Unpublished M.Phil. Thesis, Central Department of Populatio Studies), Tribhuvan University, Kathmandu.

Kurtz, S. P., Surratt, H. L., Inciardi, J. A., \& Ki, M. C. (2004). Sex work and “date” violence. SAGE journals, 10 (4), 357-385. doi:org/10.1177/1077801204263199

Luchters, S., Bosire, W., Feng, A., Richter, M. L., King’ola, N., Ampt, F., et al. (2016). “A baby was an added burden": Predictors and consequences of unintended pregnancies for female sex workers in Mombasa, Kenya: A mixed-methods study. PLoS One, 11 (9), 1-20. doi: 10.1371/journal.pone.0162871

Ministry of Health and Population (MoHP). (2010). National targeted intervention operational guideline: female sex workers. Kathmandu: National Centre for AIDS and STI Control. Retrieved from http://www.ncasc.gov. np/ncasc/Other\%20 publications/TI/Volume_3\%20_FSW.pdf 
Misganaw, A. C., \& Worku, Y. A. (2013). Assessment of sexual violence among street females in Bahir-Dar town, North West Ethiopia: a mixed method study. BMC Public Health, 13, 13-825.

National Institute of Mental Health (NIMH). (2013). Eating disorders (September 20, 2017). Retrieved from http://www.nimh.nih.gov/health/topics/eating-disorders/index.shtml

Phrasisombath, K., Faxelid, E., Sychareun, V., \& Thomsen, S. (2012). Risks, benefits and survival strategies-views from female sex workers in Savannakhet, Laos. BMC Public Health. doi:org/10.1186/1471-2458-12-1004, 1-12

Ribeiro, M., \& Sacramento, O. (2005). Violence against prostitutes: Findings of research in the Spanish-Portuguese Frontier Region. European Journal of Women's Study, 12 (1). doi:/abs/10.1177/1350506805048856

Schwartz, S., Papworth, E., Thiam-Niangoin, M., Abo, K., Drame, F., Diouf, D., et al. (2015). An urgent need for integration of family planning services into HIV care: the high burden of unplanned pregnancy, termination of pregnancy, and limited contraception use among female sex workers in Côte d'Ivoire. J Acquir Immune Defic Syndr., 68 (Supplement 2), 91-98.

Semple, S. J., Stockman, J. K., Pitpitan, E. V., Strathdee, ,. S., Chavarin, C. V., Mendoza, D. V., et al. (2015). Prevalence and correlates of client-perpetrated violence against female sex workers in 13 Mexican cities. PLoS ONE, 10 (11), 1-15. doi.org/10.1371/journal.pone.0143317

Shannon, K., Kerr, T., Strathdee, S. A., Shoveller, J., Montaner, J. S., \& Tyndall, M. W. (2009, March 8). Prevalence and structural correlates of gender based violence among a prospective cohort of female sex workers. BMJ. doi:org/10.1136/bmj.b2939, 1-8

UNAIDS. (2004). AIDS in Asia: The MAP Report. UNAIDS. Retrieved from http://data.unaids.org/una-docs/map_aidsinasia_11jul04_en.pdf

UNFPA, AFPPD, Government of Japan. (2003). Violence against women in south asia a regional analysis. Kathmandu: UNFPA.

UNICEF. (2001). A Reference kit violence against women and girls in South Asia. . Kathmandu: UNICEF.

Waltman, M. (2011). Prohibiting sex purchasing and ending trafficking: The Swedish prostitution law. Michigan Journal of International Law, 33 (1), 133-157. Retrieved from http://repository.law.umich.edu/mjil/vol33/iss1/507

Weldegebreal, R., Melaku, Y. A., Alemayehu, M., \& Gebrehiwot, T. G. (2015). Unintended pregnancy among female sex workers in Mekelle city, northern Ethiopia: A crosssectional study. BMC Public Health, 15. doi: 10.1186/s12889-015-1366-5

WHO. (2012). Prevention and treatment of HIV and other sexually transmitted infections for sex workers in low-and middle-income countries. WHO. Retrieved from http://www.who.int/about/licensing/copyright_form/en/index.html

Yadav, S. (2008). Sex and the city. the bmj Opinion. Retrieved from https://blogs.bmj.com/bmj/2008/12/09/siddhartha-yadav-sex-and-the-city/

Yazdkhasti, M., Pourreza, A., Pirak, A., \& Abdi, F. (2015). Unintended pregnancy and its adverse social and economic consequences on health system: A narrative review article. Iran J Public Health, 44 (1), 12-21. 
Zhang, X.-D., Kennedy, E., Temmerman, M., Li, Y., Zhang, W.-H., \& Luchters, S. (2014). High rates of abortion and low levels of contraceptive use among adolescent female sex workers in Kunming, China: A cross-sectional analysis. The European Journal of Contraception \& Reproductive Health Care, 19 (5), 368-378.

Note: Views and opinions expressed in this article are the personal views of author. 